\title{
Partnering with the industry: the Olympic laboratory model
}

David A Cowan and Campbell P Barker speak to Ryan De Vooght-Johnson at Bioanalysis in May 2012 about the partnership between industry and academia for the setup and running of the doping-control laboratory for the London 2012 Olympic Games.

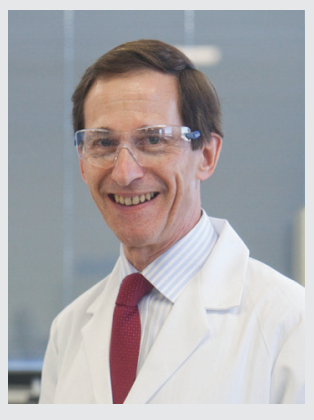

David A Cowan is Director of the London 2012 anti-doping laboratory as well as Director of the King's College London Drug Control Centre, the UK's only WADA-accredited anti-doping laboratory, and Head of the Department of Forensic Science and Drug Monitoring. Cowan co-founded the Drug Control Centre in 1978 and became its Director in 1990. He has published extensively in the field of pharmaceutical analysis, especially as it relates to detecting drug administration in sport, and was awarded a personal chair in pharmaceutical toxicology in 1996. Cowan became Head of the Department of Forensic Science and Drug Monitoring at King's College London in 2002. He has served on a number of national and international committees, including the Council of Europe Working Party Investigating Drug Abuse in Sport that led to the first World Anti-Doping Convention, the Laboratory Representative on the International Olympic Committee's Medical Commission, and WADA's Laboratory Accreditation Subcommittee. He is a member of the Crippen Club for Distinguished Toxicologists. In 1998 he was awarded the IOC Trophy for Sport Ethics by the BOA. He was a founding member of the World Association of Anti-Doping Scientists and became its first President serving on its Executive Board between $200 \mathrm{I}$ and 2004. He was a Visiting Laboratory Director at the Salt Lake City Winter Olympic Games 2002, where the first novel erythropoiesis-stimulating protein (NESP) positive was discovered. He was also a senior advisory scientist at both the Turin Winter Olympic Games in 2006 and the Beijing Olympic Games in 2008. He was also a member of the IOC Medical Commission for the Sydney Olympic Games in 2000 and the Vancouver Winter Olympic Games in 2010. The Drug Control Centre undertook the sample analysis during the 2002 Manchester Commonwealth Games and Cowan was Co-Director of the laboratory for the Commonwealth Games in Kuala Lumpur in 1998. Cowan, who has directed the laboratory at King's College London for many years, was a member of the bid team making the presentation to the International Olympic Committee in February 2005.

Campbell P Barker has been leading GlaxoSmithKline's delivery of the London 2012 laboratory services since September 2009. Prior to that time he was Director of Global Strategic Projects in GlaxoSmithKline's Consumer Healthcare business from 2006, and from 1994 to 2006 he worked in R\&D for Procter \& Gamble. Barker holds a PhD in chemistry from the University of Durham.

Q I understand that this is the first time a pharmaceutical company \& a university anti-doping laboratory have partnered to provide the drugs-testing services for any Olympic Games. How did the idea for the partnership come about?

David A Cowan (DAC): Although King's College London (KCL) has a well-established World Anti-Doping Agency (WADA)-accredited Drug Control Centre, there was insufficient space to be able to equip and staff for the operation required for an Olympic and Paralympic Games. KCL and the London Organizing Committee of the Olympic and Paralympic Games (LOCOG) spent approximately 1 year looking for suitable space. The Head of KCL Business contacted me one evening and asked whether I would be happy working with GlaxoSmithKline (GSK), since some space had recently been vacated at the GSK facilities in Harlow, UK. Coincidentally, at the same time, the LOCOG and GSK were having discussions about potential sponsorship of the Games. Within a relatively short time, an agreement was reached between LOCOG and GSK and a back-to-back agreement between GSK and KCL was reached to provide the doping control analytical services for the Games.

\section{David A Cowan*1 \\ \& Campbell P Barker ${ }^{2}$ \\ 'Department of Forensic Science \& Drug Monitoring, King's College London, 150 Stamford Street, London, SEI 9NH, UK \\ ${ }^{2}$ GlaxoSmithKline, GSK House, \\ Brentford, Middlesex, TW8 9GS, UK \\ *Author for correspondence: \\ E-mail: david.a.cowan@kcl.ac.uk

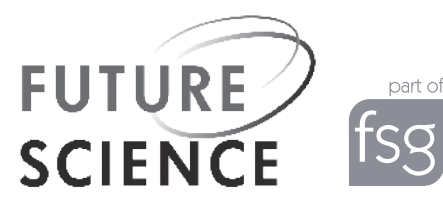


Campbell P Barker (CPB): GSK was approached by London 2012 with the idea of our providing the anti-doping laboratory services in partnership with KCL. LOCOG was determined to work with David and his team at KCL to ensure that the Games are as clean as possible. As the largest private sector funder of $R \& D$ in the UK with extensive laboratory facilities in the south east, GSK was the perfect partner to help deliver this.

And how did it develop into an efficient partnership between $\mathrm{KCL}$ and GSK?

DAC: Using GSK's project management experience, GSK worked with KCL's Drug Control Centre staff, LOCOG and UPS who are the logistics company that are responsible for doping-control sample delivery to the laboratory, to understand the details of the project. A project management team was put in place and a detailed plan was developed and implemented. Communication was key.

CPB: There was lots of hard work and commitment from both sides. After an initial 'gettingto-know-you' phase in late 2009 in the run-up to signing contracts and announcing our partnership, David and I kicked off the full project team in January 2010. We made quite an event out of this, taking the chance to bring along key stakeholders from London 2012 (Richard Budgett, the Chief Medical Officer for London 2012 as well as an Olympic Gold medalist) and from WADA (Olivier Rabin, the Scientific Director) who could communicate the significance of this ground-breaking partnership and the importance of anti-doping to the integrity of sport and the health of athletes. We then dived straight into the detailed day-to-day work that pushed the project forward. That's where - in my opinion - the partnership was forged.

How were the responsibilities divided between $\mathrm{KCL}$ and GSK?

DAC \& CPB: KCL brings expertise in relation to anti-doping. GSK's support will allow testing to be run on an industrial scale - bringing in knowledge about how to run a facility $24 \mathrm{~h}$ a day and manage effective and efficient shift changes.

What do you see as the benefits to $\mathrm{KCL}$ ?

DAC: First, having GSK as a tier three sponsor meant that the cost of establishing the laboratory anti-doping services was met by them, thereby greatly simplifying the process that confronts most Olympic analytical laboratories. GSK's knowledge and experience of large-scale operations also provided KCL with a huge resource base that it would otherwise have had to find. And finally, method development was encouraged and supported, which is important for a research-focused institution such as KCL, as well as beneficial also for GSK and legacy in that it helped reduce the number of analytical instruments that otherwise would have been required.

Q And the benefits to GSK?

CPB: GSK is very proud to have been chosen to provide a service that is so integral to the integrity of the Games and the health of the athletes. Providing the anti-doping services to the London 2012 Olympic and Paralympic Games presents GSK with a 'once-in-a-lifetime' opportunity to make a practical, material contribution to 'the greatest show on Earth' when it comes to our home city. Science plays a key role in ensuring the Games are conducted to the highest ethical standards, that the Games are as clean as possible and that athletes can lead healthier lives.

GSK's designation as Official Laboratory Services Provider also provides a springboard to drive change in our organization and the perception of GSK outside the organization. We are determined to make our company more responsive, more flexible and more open. London 2012 provides a catalyst to accelerate and deepen that change. The Olympic and Paralympic ideals of people striving to achieve their best are core to those of GSK as we strive to deliver vaccines and medicines that help patients to do more in their lives. There is great alignment in these values.

Q And what will be the benefits to the overall effectiveness of doping testing for the 2012 Olympic Games?

DAC: More tests than ever before, as well as super-fast and super-sensitive, 24-h testing. GSK is bringing expertise of industrial-scale operation to support this.

CPB: We also hope to create the model for anti-doping services for future Games.

What particular challenges did you encounter when forming the partnership \& how did you overcome them? 
DAC: Two very different organizations are coming together in this partnership. One is a major international commercial pharmaceutical company and the other an equally successful international academic organization, and each has a very different mode of operating.

CPB: One major challenge was ensuring that the partnership delivered technical innovation and delivered it on time. We have been able to make significant technical advances - partly through discretionary funding from GSK and access to our facilities - and adapt the plan to keep delivery on track. It was important that we avoided the pitfall of seeing innovation and quality of delivery as a trade-off.

Q With the industry partnership, how did you ensure that the laboratory's autonomy was maintained?

DAC: It is vital that the anti-doping services retain their independence. This is a requirement under the accreditations of the laboratory that comprise ISO 17025 as a testing laboratory accredited by the UK Accreditation Service, an organization that forms part of the International Laboratory Accreditation Co-Operation grouping as well as WADA. To ensure this, GSK has agreed that with effect from the start of 2012, the laboratory is an occupier of facilities provided by GSK and directed by me as a member of KCL staff.

Q It has been widely reported that the anti-doping laboratory will test the most samples of any Olympic Games to date. How many samples are anticipated to be tested and what logistical challenges does this present? How have you setup the laboratory to accommodate this large number of samples?

DAC: We expect to test more than 6000 samples during the Games, which will amount to a 24 h, 7-days-a-week operation. GSK has brought commercial know-how to ensure efficient shift change-over, industrial scale of operation and bespoke equipment specified (and, in some cases, developed) by KCL to allow super-fast, super-sensitive testing.

The laboratory has been described as the most high-tech in the history of the Olympic Games. Could you explain what equipment will be used for sample preparation and analysis?
DAC: Our analytical and organizational approach has been to collect comprehensive data, especially using the LC-HRMS approach, which will facilitate 'data-mining', if suggestions of misuse of new designer drugs become apparent, to search the acquired data to identify or refute suggestions of such misuse. These substances would not be detected in normal targeted drug screens that look only for specific substances. This should provide a greater deterrent to drug misuse than ever before.

Automation, in the form of a laboratory information management system on a powerful database and mirrored hardware with offsite backup, has been used to help maintain a secure chain-of-custody of the samples, sample aliquots and data relating to the samples from the moment of receipt through to reporting and subsequent secure storage of the remaining sample and data.

Barcoding and the laboratory information management system are being used throughout in order to reduce the need for manual entry of numerical data and thereby minimize the risk of transcription error or sample mismatch.

New GC-MS/MS and LC-HRMS screening is being used for all samples.

Q Is this a model that you would promote to other doping-control laboratories and to industry? And if so, why?

CPB: We will share our combined knowledge and lessons learnt, especially with the International Olympic and Paralympic Committees and WADA. We hope that we will create the design for future Games.

What would you do differently for the next Olympic Games?

CPB: It is too early to draw firm conclusions. We're confident that we will gain lots of knowledge, which we will pass on.

Q A large part of the London bid for the Olympic Games was about leaving a lasting legacy for sport in London. What legacy do you hope this partnership and the resulting laboratory will leave?

CPB: There is already legacy from GSK's involvement with London 2012 in that it has brought the company closer to the world of anti-doping. GSK has already signed a groundbreaking agreement with WADA to provide 
